ORIGINAL

\title{
Altered allergic cytokine and antibody response in mice treated with Bisphenol A
}

\author{
Mohammad Alizadeh', Fusao Ota', Kazuo Hosoi', Makoto Kato ${ }^{3}$, Tohru Sakai', and \\ Mohammed A. Satter ${ }^{4}$ \\ 'Department of Preventive Environment and Nutrition, ${ }^{2}$ Department of Molecular Oral Physiology, and \\ ${ }^{3}$ Department of International Public Health Nutrition, Institute of Health Biosciences. The University \\ of Tokushima Graduate School Tokushima, Japan; and ${ }^{4}$ Institute of Food Science and Technology, Room \\ No.1, BCSIR, Dhanmondi, Dhaka-1205, Bangladesh
}

\begin{abstract}
The Objective of this study was to elucidate if Bisphenol A (BPA) administration modulates $T$ helper (Th) cell component of immune responses in a mouse challenged with ovalbumin (OVA), a major food antigen. BALB/c mice, (6 weeks old, female) were orally given either OVA (OVA-fed) or water (Water-fed), immunized intraperitoneally with OVA and injected with either BPA in corn oil or the vehicle alone. After subsequent $2^{\text {nd }}$ immunization, serum titers of total IgE, OVA-specific IgE, IgG, IgG1 IgG2a and ability of their splenocytes for production of interferon (IFN) $-\gamma$, interleukin (IL) 4 and IL-12 were examined by ELISA. Lymphocyte proliferation assay against concanavalin $\mathrm{A}$ (Con $\mathrm{A}$ ) or OVA was also performed for ${ }^{3} \mathrm{H}$-Thymidine incorporation. In Water-fed groups, treatment with BPA resulted in lower titers of total IgE $(P<0.01)$ and higher levels IgG2a $(P<0.05)$ followed by a higher IFN- $\gamma(P<0.05)$ and IL-12 $(P<0.05)$ with an intact IL-4. When OVA-fed groups were examined, the compound did not change production of total and OVA-specific IgE and -IgG2a but resulted in lower production of IFN- $\gamma(P<0.05)$. Also, BPA resulted in impaired lymphocyte proliferation to Con $A$ in Water-fed groups $(P<0.05)$ but not in tolerated animals. The findings indicate that BPA results in augmentation of Th1 immune responses but no significant effect on an established tolerance to OVA. J. Med. Invest. 53 : 70-80, February, 2006
\end{abstract}

Keywords : BPA, food allergy, OVA, IgE, IgG2a, cytokines

\section{INTRODUCTION}

Oral tolerance is defined as an inhibition of specific immune responsiveness to subsequent parenteral injection of a protein to which an individual or animal has been previously exposed via the oral route. This has been considered as a possible therapeutic ap-

Received for publication September 21, 2005 ; accepted November 30, 2005.

Address correspondence and reprint requests to Fusao Ota, Department of Preventive Environment \& Nutrition, Institute of Health Biosciences, The University of Tokushima Graduate School, Kuramoto-cho, Tokushima 770-8503, Japan and Fax:+81-88-633-9428. proach to mange adverse immune functions such as autoimmune diseases and allergies including food allergies (1-3). Recent studies have suggested that a variety of factors determine the nature of tolerance induced following the oral administration of antigens, but possible factors involved in the induction or breakdown of oral tolerance are poorly understood.

Allergic diseases are hypersensitivity disorders, some of which are known to be associated with the production of specific IgE to allergens of environmental sources. Levels of higher serum IgE than normal are often found in patients with type I allergic 
diseases (4-6). The diseases have been reported to involve at least $20 \%$ of the population in industrialized countries with a variety of clinical symptoms (7-8). Food intolerance, including food allergy, has recently been reported to occur more frequent than ever. Although it occurs in around 1-2\% of the adult population only a small proportion of this number is truly allergic to food (9). In children, the incidence of food intolerance is estimated at 5-7\%, though most outgrow this by school age and IgE-mediated food allergy is about $1-2 \%$ (9). Increasing prevalence of allergic diseases appears to be influenced by recent changes of life style and dietary habits in the past decades, judging from their rarity before the World War II (10-12).

Recent reports suggest that endocrine disruptors (environmental hormones), chemicals that disrupt endocrine function, may pose a growing threat to human and wildlife health. These compounds can modulate both the endocrine and immune systems resulting in alteration of homeostasis, reproduction, development and behavior (13-16).

Among these compounds, Bisphenol A (BPA, 2, 2-bis (4-hydroxyphenyl) propane) which is widespread in the environment has been receiving increased attention due to high potential of exposure to human. It is widely used in the manufacture of polycarbonate plastics and food containers (17). It is also a material commonly employed in manufacture of many products including adhesives, and plastic dental sealants. Recently, a study reported that BPA was found in $95 \%$ of the urine samples the first involving a reference human population (18). Another report indicated a $1.2 \mu \mathrm{g} /$ day for a median daily urinary excretion of BPA and a $0.23 \mu \mathrm{g} / \mathrm{kg} /$ day for a maximum daily intake per body weight (19).

Nevertheless, the current literature fails to offer adequate explanations in association with underlying factors affecting occurrence of allergies including food allergies. Also, little is known about a possible role (s) of the factors, in particular environmental disruptors, on prevalence of the allergic diseases. Therefore, considering the wide use of BPA in the industries, we aimed to elucidate if BPA administration modulates Th cell component of immune responses in a mouse challenged with ovalbumin(OVA), a major food antigen. Thus, the objective of the present study was to examine the effects of BPA on cellular and humoral immune responses to OVA either with or without an induced tolerance to the antigen in a mouse model.

\section{MATERIALS AND METHODS}

\section{Animals, diets and husbandry}

Specific pathogen free BALB/c mice at 6 week of age, weighing 15-20 gram, were purchased (Japan SLC, Inc., Shizoka, Japan) and fed on a commercial diet (Oriental Yeast Co. Ltd., Tokyo, Japan) for 1 week. They were randomly divided into two groups OVAtolerant (OVA-fed) and-nonetolerant (Water-fed) groups. The mice in each group were further subdivided into two subgroups, BPA-treated and Non-treated. All animals were fed with a diet containing $20 \%$ casein,(Table 1) as sole source for protein (\% of $\mathrm{w} / \mathrm{w}$ ) during the whole experimental period. The diet was made into dough with half of its weight in water. The animals were housed in a room with a temperature maintained at $22 \pm 2^{\circ} \mathrm{C}$ on a 12 hour light/dark cycle. Every 2nd day at a set time food intake and body weight was measured, and food and water renewed. The study was approved by the Animal Research Ethics Committee at The University of Tokushima, Japan.

Table 1. Composition of the diet used

\begin{tabular}{|c|c|}
\hline Constituent $(\mathrm{g} / \mathrm{kg})$ & Amount $(\mathrm{g})$ \\
\hline Casein & 200 \\
\hline Carbohydrate $^{1}$ & 670 \\
\hline Cellulose & 20 \\
\hline Mineral mixture $^{2}$ & 50 \\
\hline Vitamin mixture $^{3}$ & 10 \\
\hline Corn oil $^{2}$ & 50 \\
\hline
\end{tabular}

${ }^{1}$ Starch : sucrose, $2: 1$ ratio

${ }^{2}$ The mixture consists of (mg/kg diet): $\mathrm{CaHPO}_{4}, 2 \mathrm{H}_{2} \mathrm{O}, 7,280: \mathrm{KH}_{2} \mathrm{PO}_{4}$, 12,860; $\mathrm{NaH}_{2} \mathrm{PO}_{4}, 4,680 ; \mathrm{NaCl}, 2,330$; Ca-lactate, 17,550; Fe-citrate, 1,590; $\mathrm{MgSO}_{4}, 3,590 ; \mathrm{ZnCO}_{3}, 55 ; \mathrm{MnSO}_{4} .4-6 \mathrm{H}_{2} \mathrm{O}, 60 ; \mathrm{CuSO}_{4} .5 \mathrm{H}_{2} \mathrm{O}, 15 ; \mathrm{KI}, 5$. ${ }^{3}$ The composition is expressed in units or milligrams of vitamins per kg of diet; Thiamine- $\mathrm{HCl}$, 12; riboflavin, 40; pyridoxine-HCl, 8 ; vitamin $\mathrm{B}_{12} 0.005$; ascorbic acid, 300 ; D-biotin, 0.2 ; folic acid ; 2 ; calcium pantothenate, 50 ; $p$-aminobenzoic acid, 50 ; niacin, 60 ; inositol, 60 ; choline chloride, 2,000 ; retinol acetate, 5,000 ; ergocalciferol, 1,000 IU ; tocopherol acetate, 50 ; menadione, 52.

\section{Experimental design for Induction of oral tolerance and immunization}

From day 21 onward for consecutive four days two groups were given orally $5 \mathrm{mg}$ of OVA ( $5 \mathrm{x}$ crystallized, Seikagaku Corp., Tokyo, Japan) dissolved in sterile distilled water $(0.5 \mathrm{ml})$ using a plastic gavage needle. The other groups (Water-fed groups) were treated in the same manner with water alone. On days 28 and 49 mice in all groups were immunized with $100 \mu \mathrm{g}$ of alum-precipitated OVA dissolved in phosphate- 
buffered saline (PBS). The experiments were repeated twice and representative results are shown.

\section{Administration of $B P A$}

BPA (Sigma Chemical Co, St Louis MO, USA) at concentration of $200 \mathrm{mg} / \mathrm{ml}$ was dissolved in corn oil (Sigma, Japan). As shown in Figure 1, from day 41 onward each mice in one of the Water-fed or OVA-fed subgroups were injected i. p. every second day and four times with the BPA solution $(0.1 \mathrm{mg} / \mathrm{g}$ of animal weight). The other two subgroups served as controls and received $0.1 \mathrm{ml}$ of the vehicle in the same manner.

\section{Preparation of Blood serum and Spleen cell suspension}

Under anesthesia with pentobarbital (Nembutal, Dainippon Pharmaceutical Co., Ltd. Japan) blood was collected from inferior vena cava and sera were separated by centrifugation and kept at $-70^{\circ} \mathrm{C}$ until used.

One week after the last immunization mice were sacrificed and spleen cell suspensions were prepared following essentially the procedure described before (20-21) with some modifications. Briefly, spleens were removed and minced by a plunger of syringe in RPMI1640 (Sigma, USA) media containing AntibioticAntimycotic (GIBCO BRL Life., USA). They were then washed by centrifugation at $4^{\circ} \mathrm{C}$. Erythrocytes in the cell suspensions were lysed by incubation with $5 \mathrm{ml}$ of $0.83 \% \mathrm{NH}_{4} \mathrm{Cl}$ in Tris- $\mathrm{HCl}(\mathrm{pH} 7.4)$ at $37^{\circ} \mathrm{C}$ for 5 minutes. All procedures were conducted under strict sterile conditions.

\section{Measurement of Total and OVA-specific IgE}

$\mathrm{IgE}$ was determined by enzyme linked immunosorbent assay (ELISA) using a quantitative ELISA Kit (BETHYL laboratories, Inc., USA) following the manufacturers' instruction. For this, immumotitre plates were coated with affinity-purified monoclonal goat antimouse IgE $(100 \mu \mathrm{l}$ of $10 \mu \mathrm{g} / \mathrm{ml})$ diluted in a buffer containing $0.05 \mathrm{M}$ carbonate-bicarbonate, $\mathrm{pH}$ 9.6. Then, serum samples diluted 100-folds, were added and the microtitre plates were incubated for 90 minutes after treatment with a blocking solution ( $\mathrm{pH}$ 8.0) containing 50mM Tris, $0.14 \mathrm{M} \mathrm{NaCl}, 0.05 \%$ Tween 20 and $1 \%$ bovine serum (TNTB). After washings with buffer solution, the plates were dispensed with goat anti-mouse IgE conjugated to horse radish peroxidase (HRP). They were washed again with the buffer and mixed with tetramethylbenzidine(TMBZ) (eBioscience, USA) and allowed to stand for 30 minutes at room temperature for color development. The reaction was stopped by adding $50 \mu \mathrm{l}$ of $1.0 \mathrm{M} \mathrm{H}_{2}$ $\mathrm{SO}_{4}$ and absorbance (OD) was measured at $450 \mathrm{~nm}$ in a micro plate reader (BIO-RAD, Japan). For calibration, serially diluted mouse IgE calibrator (BETHYL laboratories, Inc., USA) was used.

The OVA-specific IgE was measured in the same manner for the total IgE except that the wells were coated overnight at $4^{\circ} \mathrm{C}$ with $200 \mu \mathrm{l}(100 \mu \mathrm{g} / \mathrm{ml})$ of OVA dissolved in $50 \mathrm{mM}$ carbonate buffer( $\mathrm{pH} 9.6$ ) and incubated.

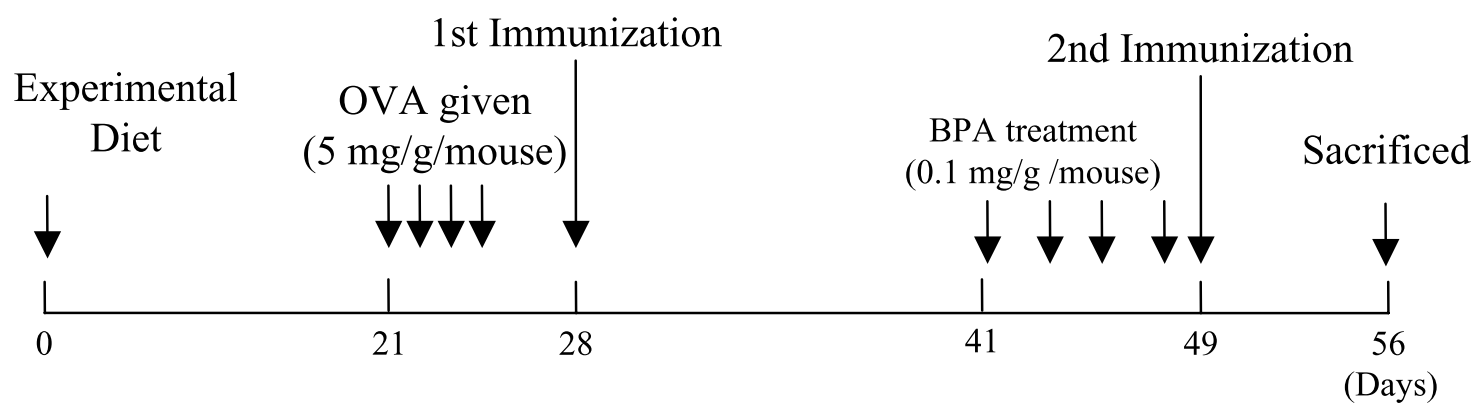

Groups:

1. Water-fed:

1. Oral administration of water + immunization without BPA treatment

2. Oral administration of water + immunization with BPA treatment

2. OVA-fed:

3. Oral administration of OVA + immunization without BPA treatment

4. Oral administration of OVA + immunization with BPA treatment

Fig. 1. Experimental design for the effects of BPA on immune functions. Mice were divided into two groups, fed with experimental diet and pretreated orally with either water or $5 \mathrm{mg} / \mathrm{d}$ of OVA for consecutive 4 days, from day 21 onwards. They were further divided into two subgroups. All the animals were immunized with $100 \mu \mathrm{g}$ of alum-precipitated OVA twice in 3 weeks intervals on days 28 and 49 . BPA-treatment was performed four times every second day starting from day 41 onwards, before $2^{\text {nd }}$ immunization with OVA, for one of each subgroup. On day 56 , mice were killed and sera were collected. 
Measurement of OVA specific IgG, IgG1 and IgG2a in Serum

OVA-specific IgG, -IgG1 and -IgG2a were also measured using ELISA. Briefly, 96 well plates were coated with OVA, as described above, and incubated overnight at $4^{\circ} \mathrm{C}$. They were then treated with the blocking solution. After four washings with TNTB the wells were added by serum samples diluted 1000 folds for OVA-specific IgG, - IgGl and 50 folds for OVAspecific IgG2a and incubated at room temperature for 90 minutes. The microtitre plates were washed again with TNTB and mixed with 2000 folds diluted goat antimouse IgG ( $\mathrm{H}$ and $\mathrm{L}$ chain specific), IgG1 $\left(\gamma_{1}\right.$ chain specific) or IgG2a ( $\gamma_{2}$ a chain specific) conjugated to alakline phophatase (Southern Biotechnology Associates, Inc. UK) and incubated for an hour at room temperature. Then, p-nitro penyl phosphate was added and followed by stopping the reaction with $150 \mathrm{mM}$ EDTA and OD was finally measured at $415 \mathrm{~nm}$.

\section{Cytokine Production}

A suspension $\left(5 \times 10^{6}\right.$ cells/well) of spleen cells in RPMI-1640 medium containing Antibiotic-Antimycotic, $25 \mathrm{mM}$ HEPES, $5 \times 10^{-5} \mathrm{M}$ 2-mercaptoethanol and $10 \%$ heat inactivated fetal bovine serum (Flow Laboratories Inc, McLean, VA, USA) was prepared and dispensed into 24 well culture plates. They were then cultured with or without $\mathrm{Con} A$ at $37^{\circ} \mathrm{C}$ incubator under an atmosphere of $5 \% \mathrm{CO}_{2}$, as described before. After $72 \mathrm{~h}$, supernatants of three cultures from each mouse were collected by centrifugation at $400 \mathrm{x} g$ and pooled for analysis of interleukin (IL)-4, interferon (IFN)- $\gamma$, and IL-12 by ELISA.

\section{Measurement s of Cytokines in Culture Supernatants}

Levels of IL-4, IFN- $\gamma$ and IL-12 in the culture supernatants of splenocytes were measured following the conventional method. In brief, microtiter plates (Nunc. Maxisorp, USA) were coated with $100 \mu \mathrm{l} /$ well of anti-mouse IL-4, IFN- $\gamma$ or IL-12 monoclonal antibodies (eBioscience, USA) by incubation overnight at $4{ }^{\circ} \mathrm{C}$. The wells were washed four times with PBS containing $0.05 \%$ Tween- 20 . Non-specific binding sites were blocked following the manufactures' instruction. After three washings, the wells were incubated for 90 minutes at $4^{\circ} \mathrm{C}$ with samples of culture supernatants. For standard curves, the plates were incubated in the same way with serially diluted recombinant mouse cytokines. The wells were washed five times with the buffer and incubated at room temperature for $90 \mathrm{~min}$ with biothinylated anti-mouse IL-4, anti-mouse IFN- $\gamma$ or anti-mouse IL-12 mono- clonal antibody (eBioscience, USA). Finally, the plates were washed and incubated for 30 minutes with HRPconjugated to avidin. They were washed again seven times with the washing buffer before addition of TMBZ as substrate. The microtitre plates were measured for absorbance at $450 \mathrm{~nm}$ in the ELISA reader after the reaction was stopped with $1 \mathrm{M} \mathrm{H}_{2} \mathrm{SO}_{4}$.

\section{Lymphocyte Proliferation Assay}

Spleen cell suspensions were prepared as described above to contain $5 \times 10^{6}$ cells $/ \mathrm{ml}$ in RPMI- 1640 medium containing Antibiotic-Antimycotic, $25 \mathrm{mM}$ HEPES, $5 \times 10^{-5} \mathrm{M}$ 2-mercaptoethanol and $10 \%$ heat inactivated fetal bovine serum (Flow Laboratories Inc., McLean, VA, USA). Cells $\left(2.5 \times 10^{6}\right.$ cells/well) were cultured in triplicates in the medium with either Con A $(10 \mu \mathrm{g} /$ $\mathrm{ml})$ or OVA $(100 \mu \mathrm{g} / \mathrm{ml})$ at $37^{\circ} \mathrm{C}$ for $96 \mathrm{~h}$ in a humidified atmosphere of $5 \% \mathrm{CO}_{2}$ and $95 \%$ air. Control cultures contained only the medium. For the last 17 hours the cells were exposed to $2 \mu \mathrm{Ci}$ of $\left[{ }^{3} \mathrm{H}\right]$ thymidine(specific activity: $74 \mathrm{GBq} / \mathrm{mmol}$, Amersham Pharmacia Biotech, England). The Cells were harvested using a glass filter and counted for radioactivity in a direct beta counter (MATRIX $^{\mathrm{TM}}$ 9600, PACKARD, Canberra Company, USA).

\section{STATISTICAL ANALYSIS}

The Data were analyzed with SPSS for Windows (version 10) statistical package. Statistical analysis was done by the Mann-Whitney U-test. P values less than 0.05 were considered statistically significant.

\section{RESULTS}

\section{Effects of BPA on Body and Spleen weight}

Food intake did not show any difference among the groups and no visible side effects were observed after treatment with BPA (data not shown). As shown in Table 2, when animals were treated with BPA they showed an increase in body weight in both OVAfed and Water-fed groups at the end of the experiment as compared to those without BPA treatment, although the increase was not statistically significant. The mean weight gain of BPA treated mice, during the period, was 2.32 and $2.55 \mathrm{~g}$ for the Water-fed and OVA-fed groups, respectively. All groups treated with BPA showed a statistically significant increase in spleen weight $(p<0.05)$. 


\section{Effects of BPA on total and OVA-specific IgE}

To see the effects of BPA on IgE response in OVAtolerated and-none-tolerated, total and OVA-specific IgE were compared between the Water-fed and OVAfed groups with or without treatment with BPA. As shown in Figure $2 \mathrm{~A}$ and $\mathrm{B}$, when animals were given OVA orally, titers of total and OVA-specific IgE were generally higher in Water-fed groups than those in OVA-fed groups. In addition, in both Water-fed and OVA-fed groups, BPA treatment resulted in lower production of the antibodies, except among the OVA-

Table 2. Body and spleen weights of mice with or without BPA treatment

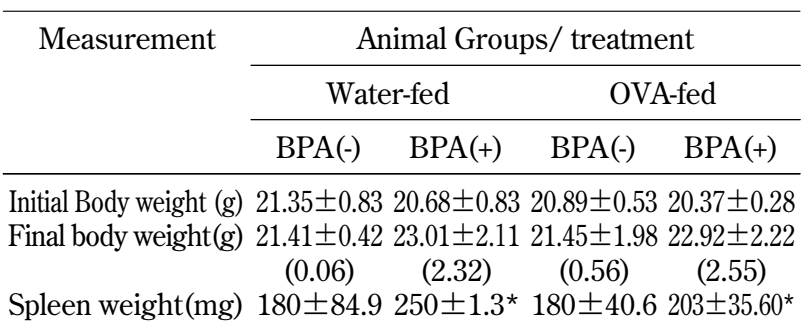

$\mathrm{BPA}(-)$ and $\mathrm{BPA}(+)$ represent animals treated and not treated with Bisphenol A, respectively. Numbers in the parentheses represent weight gain taken from 6 mice in each group, expressed as means \pm S.D. Asterisks represent $p$ value less than 0.05 versus BPA (-).
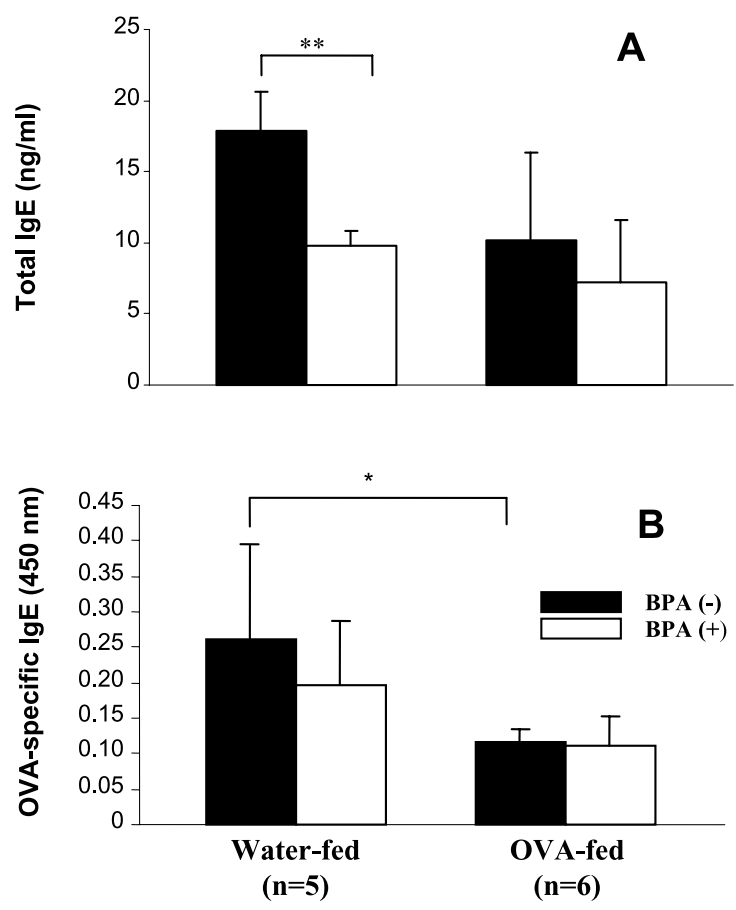

Fig. 2. Total and OVA-specific IgE in the sera of Water-fed and OVA-fed mice with or without treatment with BPA. Mice were grouped and treated as described in legend for figure 1 . The sera were used to determine total (A) and OVA-specific (B) IgE titers using ELISA as described in Materials and Methods. Water-fed and OVA-fed represent animal groups fed orally water and OVA, respectively. The black and white columns represent Non-BPA treatment and BPA treatment, respectively. Results are expressed as mean \pm S.D. (bars), $\mathrm{n}=5-6$ mice. The single and double asterisks represent $p$ values less than $0.05,0.01$, respectively. fed subgroups for OVA-specific IgE. As shown in Figure $2 \mathrm{~A}$, despite a significantly lower production of total IgE in BPA treated subgroup of Water-fed animals $(p<0.01)$, the chemical did not cause any significant change in the OVA-fed mice. A similar profile was observed for OVA-specific IgE between the two subgroups in the Water-fed groups (Figure 2B), but no statistically significant difference was noted. OVA feeding led to a lower production of OVA-specific IgE either with or without BPA treatment, but the decrease was significant in the animal group without exposure to BPA $(p<0.05)$.

\section{Effect of BPA on OVA- specific IgG, -IgG1 and-IgG2a}

We next examined the effect of BPA on production of OVA-specific IgG, -IgG1 and -IgG2a in both OVA-fed and Water-fed groups. The administration of BPA did not show any statistically significant changes in the serum levels of OVA-specific IgG both in Water-fed and OVA-fed groups (Figure 3A). However, as shown in Figure 3B, the OVA-specific IgG1 was suppressed in OVA-fed animals without BPA treatment as compared to corresponding Water-fed group with a borderline significance $(p=0.052)$ but remained unchanged in between the two other animal groups administered with BPA. In contrast, OVA-specific IgG2a was generally lower in the OVA- fed groups with or without BPA treatment than that in the Water-fed animals (Figure3C). In addition, regardless of BPA treatment, Water-fed mice showed a relatively higher production of OVA-specific IgG2a. Furthermore, IgG2a titer was significantly higher in BPA treated Water-fed animals as compared to BPA treated OVA-fed group $(p<0.05)$.

\section{Effects of BPA on cytokine production}

IL-4, IFN- $\gamma$ and IL-12 are known to have key roles in the balance of immune functions. In order to assess effects of BPA on production of these cytokines in OVAtolerated and -none-tolerated, we examined their titers in culture supernatants of splenocytes from all animal groups upon stimulation with Con A using ELISA. As shown in Figure 4A, administration of BPA to Waterfed animals resulted in an increased IFN- $\gamma$ production as compared with the control $(p<0.01)$. Also, production of IFN- $\gamma$ was remarkably increased in OVA-fed mice without BPA treatment as compared with corresponding Water-fed group $(p<0.01)$. Furthermore, within the OVA-fed groups, IFN- $\gamma$ was decreased in animals injected with BPA $(p<0.01)$.

On the other hand, when IL-4 production was examined (Figure 4B), there were no substantial differences either between the Water-fed and OVA-fed groups 
or between BPA treated and non-treated subgroups. Finally, when IL-12 was examined, it was lower in the non-BPA treated Water-fed group compared to the corresponding OVA-fed group (Figure 4C). However, in the Water-fed groups, the animals treated with BPA showed a statistically higher level of IL-12 than those not treated with BPA $(\mathrm{p}<0.01)$.

\section{Effects of BPA on lymphocyte proliferation}

To look into if and how BPA affects lymphocyte proliferation, spleen cells were stimulated with either OVA or Con A and counted for ${ }^{3} \mathrm{H}$-thymidine incorporation. As shown in Table 3 , when stimulated with Con A, the responses were generally lower in OVA-fed groups as compared to the corresponding Water-fed groups. Also, proliferation was lower in animals treated with BPA than those not treated with it. BPA resulted in significant reduction in lymphocyte proliferation in Water-fed animals $(p<0.05)$ but not in OVA-fed animals. Pre feeding with OVA resulted in significant decrease of the proliferation in mice not treated with BPA $(p<0.05)$.
Although not significant, but proliferation was rather increased with BPA treatment.

\section{DISCUSSION}

Although many reports are available regarding the effects of BPA on the reproductive organs $(14,22-23)$ less is known about its effect on the immune system. In the current work, attempts were made to examine the effects of BPA on Th cell component of immune responses to OVA. In this experiment, OVA free casein based diet was used throughout the experimental period to ensure that there were no effects attributable to OVA contaminating the diet.

BPA has been reported to reduce body weight or body weight gain and to increase organ weights such as liver, kidneys, adrenals, spleen, pituitary, and brain in weaning and adults animals (14). In agreement with the report, it was found that administration of BPA resulted in increased spleen weight. It was also

Table 3. Effects of BPA on OVA-specific and -nonspecific proliferation

\begin{tabular}{cccc|ccc}
\hline \multirow{2}{*}{ Stimulant } & \multicolumn{7}{c}{ Groups } \\
\cline { 2 - 7 } & BPA(-) & BPA $(+)$ & SI & BPA(-) & BPA $(+)$ & SI \\
\cline { 2 - 7 } & $218 \pm 70^{\mathrm{a}}$ & $126 \pm 50^{\mathrm{b}}$ & 1.7 & $136 \pm 60$ & $98 \pm 65$ & 1.4 \\
$\begin{array}{c}\text { Concanavalin A } \\
\text { (Con A) } \\
\text { Ovalbumin(OVA) }\end{array}$ & $21 \pm 6^{\mathrm{a}}$ & $18 \pm 12$ & 1.3 & $14 \pm 7^{\mathrm{b}}$ & $41 \pm 25$ & 0.3 \\
\hline
\end{tabular}

$\mathrm{BPA}(-)$ and $\mathrm{BPA}(+)$ represent animals treated and not treated with Bisphenol A, respectively. SI indicate stimulation ratio. The figures, except SI, represent radioactivity in count per minute $\left(\mathrm{cpm} \times 10^{-2}\right)$ taken from 6 mice in each group, expressed as means \pm S.D. Different letters within any of the rows represent $p$ value less than 0.05 .
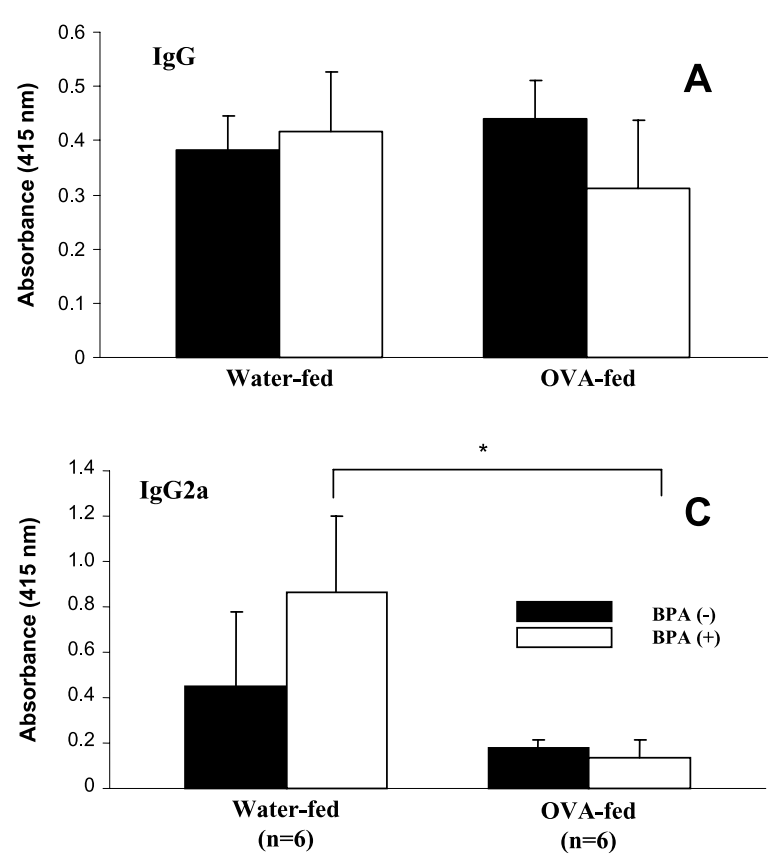

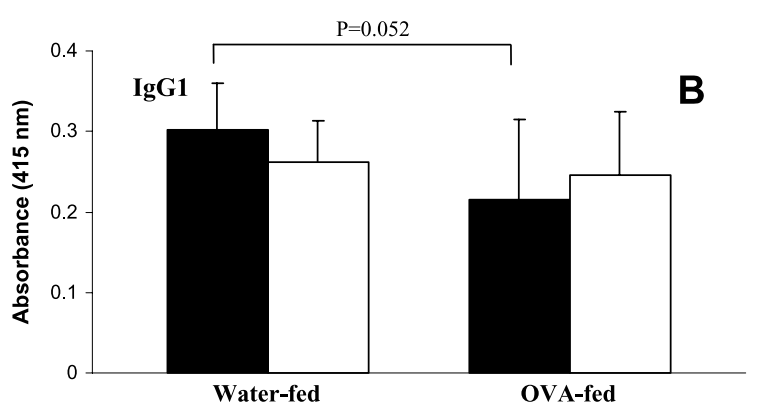

Fig. 3. OVA-specific $\operatorname{IgG}(\mathrm{A}), \operatorname{IgG} 1$ (B) and IgG2a (C) in the serum of Water-fed and OVA-fed mice with or without treatment with BPA. Mice were treated in the same manner in the legend for Figure 1. Antibodies were determined by ELISA.Water-fed and OVA-fed represent animal groups fed orally water and OVA, respectively. Results are expressed as mean \pm S.D. (bars), $\mathrm{n}=6$. An asterisk indicates a $p$ value less than 0.05 . 

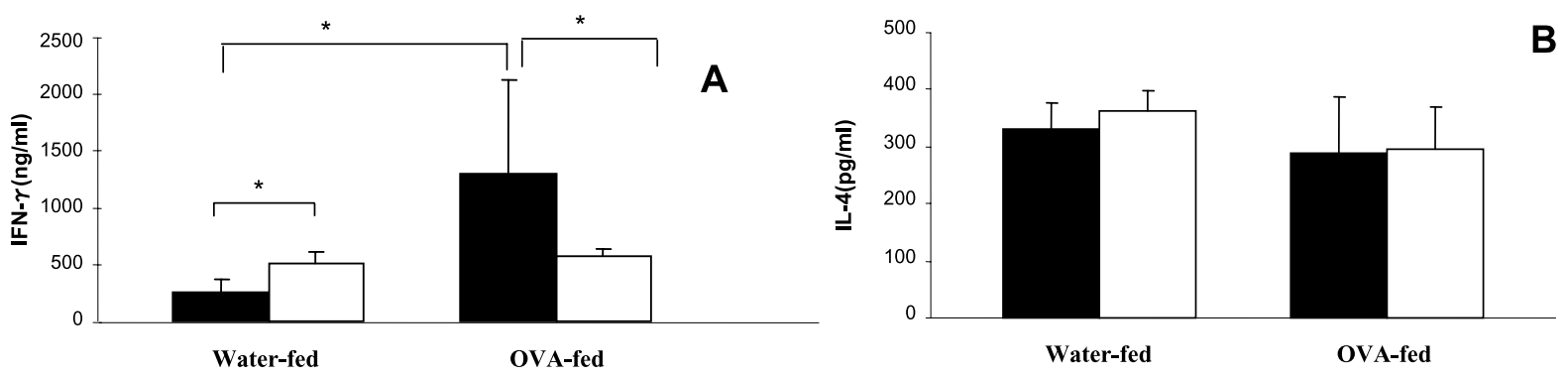

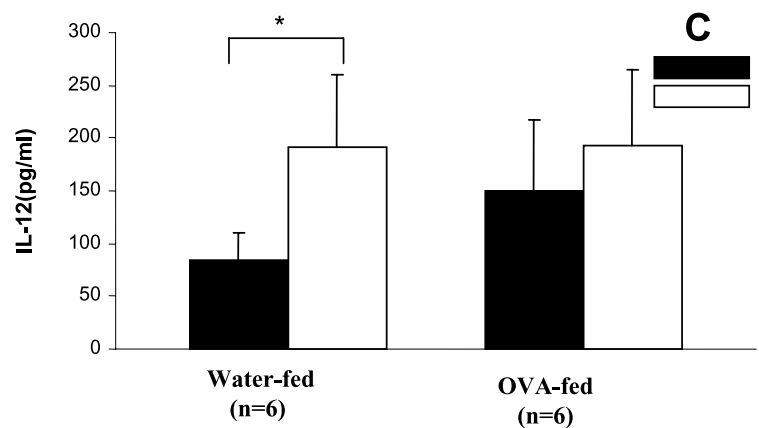

demonstrated that the animals treated with BPA showed an increase in body weight. BPA has estrogenlike activity (14) and there are report showing that different mouse strains differ in their sensitivity to estrogen (24-25). Therefore, the discrepancies observed in the weight gain and the other parameters may be due to difference in the strain of mice used and the dose and way of BPA treatment. The dose of BPA used in the present study was extremely large as compared with the levels detected in the environment (17). Nevertheless, as microgram orders of BPA were detectable in liquids collected from canned vegetables (26) and, therefore, the levels of human's exposure remains significant.

Although the biologic effect of BPA is not yet clearly understood, its ability to bind to both $\alpha$ and $\beta$ estrogen isoforms (22) makes it a potentially important modulator of immunity. However, there are reports from in vitro studies demonstrating that BPA decreased substrate adherence capacity of antigen-presenting cells such as macrophages 27) and increased nonspecific proliferation of spleen cells to Con A (28).
Fig. 4. Levels of INF-g (A), IL-4 (B) and IL-12 (C) in culture $\mathbf{B P A}(-)$
$\mathbf{B P A}(+)$ OVA-fed mice with or without treatment with BPA. Spleen cell suspensions $\left(2.5 \times 10^{6}\right)$ were prepared and cultured as described in Materials and Methods. Supernatants were collected after centrifugation and assayed by ELISA. Water-fed and OVAfed represent animal groups fed orally water and OVA, respectively. Results are expressed as mean \pm S.D. (bars), $\mathrm{n}=6$. The black and white columns represent non-BPA treatment and BPA treatment, respectively. The single asterisks represent $p$ values less than 0.01 .

A decrease in serum $\operatorname{IgE}$ response together with diminished T-cell responses is likely the hallmark of oral tolerance (29). In the present study, treatment with BPA between the two immunisations with OVA resulted in a substantial decrease in total IgE in the both Waterfed and OVA-fed groups. Judging from substantial suppression of total and OVA-specific IgE in OVA-fed groups as compared with the corresponding Water-fed groups, the tolerance was definitely induced by giving orally of OVA without exposure to BPA. This agrees with our previous observation that OVA feeding results in remarkable (21) and significant (30) suppression in total IgE levels in mice fed with a similar diet. Nevertheless, among the animals with BPA treatment the IgE suppression was not as profound as those without exposure to the chemical. Although effect of BPA on IgE production is not well understood but our finding on reduction of IgE with BPA treatment disagrees, in part, with a previous report (31) that described enhanced IgE levels in mice treated with BPA after immunisation with keyhole limpet haemocyanin. The amount of BPA used in this study ( $0.1 \mathrm{mg} / \mathrm{g}$ of mouse) was 
relatively higher than the doses used in their report (31). Also, the discrepancy, observed by us, may be cuased by other factors such as the differences in feeding, the way of adminstering with BPA and antigen used for immunization. Besides, the time distance between the last administration and sacrificing the animals is an important factor because of a high systemic clearance and a short half life of BPA.

Treatment with BPA was not associated with any alteration in the production of either OVA-specific IgG. On the other hand, our finding of suppressed IgG2a in OVA-fed animals when compared to Water-fed groups was also in good agreement with our previous observation (30). Since IgG2a is known to be dependent on Th1 activity while IgG and IgG1 are dependent on $\mathrm{Th} 2$ activity (32), our finding on augmentation of IgG2a in Water-fed mice treated with BPA, together with lower OVA-specific IgE apparently indicate shift of immune balance toward Th1 dominance. The finding was in consistent with the previous report (33) which showed hen egg lysozyme- specific IgG2a production was significantly enhanced in mice treated with BPA.

The cytokine microenvironment has several immunoregulatory properties which makes these molecules as important modulators and effectors in the immune system. In particular, multiple cytokines have been proved to be closely associated with allergic diseases including food allergies. Polyclonal T cell cytokine responses may reflect more clearly the diversity of the responses to allergens than antigen specific $T$ cell clones (34). Thus, in the current study, to promote cytokine production by splenocytes, the cells were stimulated with Con A, a polyclonal T cell mitogen, which agitated whole $T$ cell population by activating protein kinase C. These involved the measurement of Th1- and Th2type cytokine production in OVA-treated and nonetolerated animals with or without BPA administrations. IL-12 and IFN- $\gamma$ were used as markers of Th1type reactivity, and the measurement of IL- 4 was used as an index of Th2 reactivity.

Induction of IFN-g is an earlier response to oral antigen in intestinal tissue (35-36) suggesting its important role in the induction of oral tolerance (37). In the current work, in fact, splenocytes of Water-fed animals produced a significantly higher level of IFN- $\gamma$ in BPA-treated than the animals not treated but the reverse was found in OVA-fed groups. It has been reported that estrogen plays an important modulatory role in the immune system by increasing or decreasing production of cytokines and also by involving direct interaction (binding) of the hormone and hormone receptors within Th 1 and Th 2 cells (38). Also, it has been suggested that oral tolerance might be affected by estrogen treatment through alteration of intestinal immune responses (39). They demonstrated that injection of 17- $\beta$ estradiol abrogated the oral tolerance induced by oral feeding of type II collagen in mice model of collagen-induced arthritis. Furthermore, there is evidence that the outcome of transcriptional regulation at activator protein- 1 or estrogen response elements sites is dependent both on the estrogen receptor subtype involved and on the ligand (40). On the other hand, the suppression of IgE by BPA treatment was probably due to the up-regulated levels of IFN- $\gamma$ since no substantial change in production of IL-4 was observed after the treatment.

IL-12 is also known to be a key cytokine in $\operatorname{IgE}$ production by directing naive (undifferentiated) $\mathrm{T}$ cells toward Th1 polarization (41). The role of IL-12 in regulating the Th1/Th2 balance is in part its ability to induce IFN- $\gamma$ production by natural killer and Th1 cells, which in turn promotes Th1 development but suppresses Th2 development (42). BPA treatment resulted in a high production of IL-12 in either Waterfed or OVA-fed groups with a significant difference in the Water-fed groups. Regulatory effect of estrogen on cytokine secretion is dose dependent and it is clearly shown that lower doses of estrogens promote Th 1-like activity (43). The fact that BPA has weak estrogenic activity may explain the shift of immune response towards Th1 dominance via enhanced IL12 production in BPA treated animals. There is a report that functional IL-12 dependent IFN- $\gamma$ signaling pathway does not play an important role in the induction of oral tolerance (44). They showed that feeding tolerogenic doses of OVA primed for IFN- $\gamma$ production in the spleen of mice with a normal $T$ cell repertoire but tolerance was also induced normally in both $\mathrm{IFN}-\gamma$ receptor knockout (IFN- $\gamma$ R-/-) and IL-12 knockout (IL-12-/-) mice. However, we were not able to explain how a relatively higher level of IL-12 in OVA-fed mice treated with BPA was followed by lower production of IFN- $\gamma$.

To evaluate state of oral tolerance to OVA with BPA administration, we have also examined OVA-specific cytokine production in both Water-fed and OVA-fed groups with or without BPA treatment (data not shown). Our preliminary data indicated higher IFN- $\gamma$ and IL-12 and a lower, but not significant, IL-4 production in the BPA treated Water-fed animals as compared to those without the treatment. Interestingly, among the tolerated (OVA-fed) animals, no remarkable alteration of these cytokines was observed with the BPA treatment. These results indicate that the oral tolerance to OVA is in place in OVA-fed groups treated with BPA administration. 
It was previously reported in our laboratory that mice tolerated in a similarly had lower proliferation after stimulation with OVA (21) and beta-lactaglubulin (44) compared to Water-fed groups. We observed a lower proliferation against OVA in Water-fed animals treated with BPA in comparison to those not treated with it, with a remarkable enhancement of the proliferation after BPA treatment in OVA-fed animals. Moreover, there was also significant supression of proliferative responses of splenocytes when stimulated with Con $\mathrm{A}$ in Water-fed but not in OVA-fed animals after BPA treatment. This may suggest that BPA administration altered not only the cytokine response of the $\mathrm{T}$ cells but also their proliferative response. The increase of spleen weight in BPA treated tolerant mice may reflect the enhanced proliferation observed in the group. A previous report indicated that BPA enhanced proliferative response of splenocytes to Con $A$ when they were simultaneously exposed to BPA (45). Thus, it is speculated that administration of BPA appears to somehow affect function of $T$ cells resulting induction of lymphocyte proliferation in the spleen.

Cells of the immune system are known to respond to sex hormones, including estrogens (46). BPA can activate the estrogen receptor alpha (47) but its affinity to the receptor is about 26 -fold less than other estrogens (22). Besides, it has been reported that only 100 times smaller dose of estradiol than that of BPA was required for enhancement of lymphoid cell proliferations and both Th1 and Th2 responses (22). Moreover, it is worthy to note that our findings can not be infulenced by the gender of mice used since endogenous estrogen has no additional effects on antigen-specific proliferative responces of lymphoid cells (33).

In conclusion, the present results demonestrate that the OVA-specific and none-specific Th1 dependent immune responses were potentially enhanced by exposure to BPA without an induced tolerance to OVA. The results suggest that environmental factors as well as dietary factors, in particular amount of dietary protein intake shown by us previously $(21,30)$, are influential in the recent changes in prevalence of the allergic diseases including food allergies. However, the particular mechanism(s) by which BPA modulates immune responses to OVA should be clarified involving varying experimental conditions, including dose response and timing of BPA given, and strains of animals used.

\section{ACKNOWLEDGEMENTS}

This work was supported in part by Grants-in
Aid (Nos. 11691211 and 14657017) from the Ministry of Education, Culture, Sports and Technology of Japan, and also partly supported by a grant from Yakult Ltd., Japan. The authors wish to thank Dr. M.Yamato for his kind advices during the study and Mrs. A. Takeoka for her administrative work.

\section{REFERENCES}

1. Faria AM, Weiner HL: Oral tolerance: mechanisms and therapeutic applications. Adv Immunol 73: 153-264, 1999

2. $\mathrm{Wu} \mathrm{HY}$, Weiner HL : Oral tolerance. Immunol Res 28(3) : 265-84, 2004

3. Mayer L, Shao L:Therapeutic potential of oral tolerance. Nat Rev Immunol 4(6) :407-19, 2004

4. Corry DB, Kheradmand F: Induction and regulation of the IgE response. Nature 25 ; 402(Suppl 6760): B 18-23, 1999

5. Savelkoul HF, Neijens HJ : Immune responses during allergic sensitization and the development of atopy. Allergy 55(11) : 989-97, 2000

6. van der Velden VH, Laan MP, Baert MR, de Waal Malefyt R,Neijens HJ, Savelkoul HF : Selective development of a strong Th2 cytokine profile in high-risk children who develop atopy: risk factors and regulatory role of IFN-gamma, IL-4 and IL-10. Clin Exp Allergy 31(7):997-1006, 2001

7. Eum SY, Haile S, Lefort J, Huerre M, Vargaftig BB: Eosinophil recruitment into the respiratory epithelium following antigenic challenge in hyper$\mathrm{IgE}$ mice is accompanied by interleukin 5dependent bronchial hyperresponsiveness. Proc Natl Acad Sci U S A 19 ; 92 (26) : 12290-4, 1995

8. Coyle AJ, Wagner K, Bertrand C, Tsuyuki S, Bews J, Heusser C:Central role of immunoglobulin (Ig) $\mathrm{E}$ in the induction of lung eosinophil infiltration and Thelper 2 cell cytokine production: inhibition by a non-anaphylactogenic anti-IgE antibody. J Exp Med 1 ; 183(4) : 1303-10, 1996

9. Kagan RS : Food Allergy : An Overview. Environ Health Perspect $111: 223-225,2003$

10. Strobel, S : Oral tolerance : Immune response to food antigens. In : Metcalfe DD, Sampson HA, Simon RA. (Ed.), Food Allergy Adverse Reactions to food antigens and food Additives, Blackwell Science, Boston, 1997,pp. 107-35

11. Hijazi N, Abalkhail B, Seaton A: Diet and childhood asthma in a society in transition:a study in urban and rural Saudi Arabia. Thorax 55(9):775-9, 2000

12. Chandra RK. (ed.): Food allergy and nutrition 
in early life: implications for later health. Proc Nutr Soc 59(2) : 273-7, 2000

13. Al-Hiyasat AS, Darmani H, Elbetieha AM: Effects of bisphenol A on adult male mouse fertility. Eur J Oral Sci 110(2) : 163-7, 2002

14. Tyl RW, Myers CB, Marr MC, Thomas BF, Keimowitz AR, Brine DR, Veselica MM, Fail PA, Chang TY, Seely JC, Joiner RL, Butala JH, Dimond SS, Cagen SZ, Shiotsuka RN, Stropp GD, Waechter JM:Three-Generation Reproductive Toxicity Study of Dietary Bisphenol A in CD Sprague-Dawley Rats. Toxicol Sci 68(1) : 12146, 2002

15. Sawai C, Anderson K, Walser-Kuntz D : Effect of bisphenol A on murine immune function : modulation of interferon-gamma, IgG2a, and disease symptoms in NZB X NZW F1 mice. Environ Health Perspect 111(16): 1883-7, 2003

16. Funabashi T, Kawaguchi M, Furuta M, Fukushima A, Kimura F: Exposure to bisphenol A during gestation and lactation causes loss of sex difference in corticotropin-releasing hormone-immunoreactive neurons in the bed nucleus of the stria terminalis of rats. Psychoneuroendocrinology 29(4) : 475-85, 2004

17. Ben-Jonathan N, Steinmetz R: Xenoestrogens:the emerging story of Bisphenol A. Trends Endocrinol. Metab $9: 124-7,1998$

18. Calafat AM, Kuklenyik $Z$, Reidy JA, Caudill SP, Ekong J, Needham LL: Urinary concentrations of Bisphenol A and 4-Nonylphenol in a human reference population. Environ Health Perspect 113(4) : 391-5, 2005

19. Arakawa C, Fujimaki K, Yoshinaga J, Imai H, Serizawa S, Shiraishi H: Daily urinary excretion of bisphenol A. Environ Health Prevent Med $9: 22-26,2004$

20. Petro TM, Zhang S:The effect of moderate protein malnutrition on murine T cell cytotkine production. Nutr Res 17 : 51-64, 1997

21. Satter MA, Sakai K, Ahmed S, Yoshino K, Yamamoto S, Shimizu Y, Ota F: Low-protein diet induces oral tolerance to ovalbumin in Mice. J Nutr Sci Vitaminol (Tokyo) 48(1) : 51-8, 2002

22. Gould JC, Leonard LS, Maness SC, Wagner BL, Conner K, Zacharewski T, Safe S, McDonnell DP, Gaido KW : Bisphenol A interacts with the estrogen receptor alpha in a distinct manner from estradiol. Mol Cell Endocrinol 25 ; 142(1-2) : 203-14, 1998

23. MacLusky NJ, Hajszan T, Leranth C : The environmental estrogen bisphenol a inhibits estradiol- induced hippocampal synaptogenesis. Environ Health Perspect 113(6) : 675-9, 2005

24. Spearow JL: In Polycystic Ovary Syndrome, R. J. Chang (Ed.) Springer-Verlag, New York, 1996, pp. $1-20$

25. Spearow JL, Doemeny P, Sera R, Leffler R, Barkley $\mathrm{M}$ : Genetic variation in susceptibility to endocrine disruption by estrogen in mice. Science 20 ; 285(5431) : 1259-61, 1999

26. Brotons JA, Olea-Serrano MF, Villalobos M, Pedraza V, Olea N: Xenoestrogens released from lacquer coatings in food cans. Environ Health Perspect 103(6) : 608-12, 1995

27. Segura JJ, Jimenez-Rubio A, Pulgar R, Olea N, Guerrero JM, Calvo JR: In vitro effect of the resin component bisphenol A on substrate adherence capacity of macrophages. J Endod 25 (5) : 341-4, 1999

28. Jontell M, Hanks CT, Bratel J, Bergenholtz G: Effects of unpolymerized resin components on the function of accessory cells derived from the rat incisor pulp. J Dent Res 74(5):1162-7,1995

29. Chen Y, Inobe J, Marks R, Gonnella P, Kuchroo VK, Weiner HL:Peripheral deletion of antigen-reactive T cells in oral tolerance Nature $21 ; 377(6546)$ : 257, 1995

30. Ahmed S, Satter MA, Yamamoto S, Maeda K, Minato Y, Ota F : Further evidence regarding the effect of dietary protein on oral tolerance against beta-lactoglobulin through Th1-mediated immune response in mice. J Nutr Sci Vitaminol (Tokyo) 49(2) : 112-9, 2003

31. Lee MH, Chung SW, Kang BY, Park J, Lee CH, Hwang SY, Kim TS : Enhanced interleukin-4 production in CD 4+ T cells and elevated immunoglobulin $\mathrm{E}$ levels in antigen-primed mice by bisphenol A and nonylphenol, endocrine disruptors : involvement of nuclear factor-AT and $\mathrm{Ca} 2+$. Immunol 109(1) : 76-86, 2003

32. Burnstein $\mathrm{H}, \mathrm{Abbas} \mathrm{A}$ : In vivo role of interleukin4 in T cell tolerance induced by aqueous protein antigen. J Exp Med 177 : 457-63, 1993

33. Yoshino S, Yamaki K, Yanagisawa R, Takano H, Hayashi H, Mori Y : Effects of bisphenol A on antigen-specific antibody production, proliferative responses of lymphoid cells, and TH1 and TH2 immune responses in mice. Br J Pharmacol 138 (7) : 1271-6, 2003

34. Haselden BM, Kay AB, Larche M : Peptidemediated immune responses in specific immunotherapy. Int Arch Allergy Immunol 122 (4) : 229-37, 2000 
35. Marth T, Strober W, Kelsall BL: High dose oral tolerance in ovalbumin TCR-transgenic mice : systemic neutralization of IL-12 augments TGFbeta secretion and T cell apoptosis. J Immunol 15 ; 157 (6) : 2348-57, 1996

36. Chen Y, Inobe J, Weiner HL: Inductive events in oral tolerance in the TCR transgenic adoptive transfer model. Cell Immunol 25; 178(1) :62-8, 1997

37. Bao M, Yang Y, Jun HS, Yoon JW : Molecular mechanisms for gender differences in susceptibility to $T$ cell-mediated autoimmune diabetes in nonobese diabetic mice. J Immunol 15 ; 168(10) : 5369-75, 2002

38. Hall JM, Couse JF, Korach KS : The multifaceted mechanisms of estradiol and estrogen receptor signaling. J Biol Chem 276 : 3686936872,2001

39. Hosoda T, Mito N, Yoshino H, Sato K:Estrogen altered oral tolerance induction in type II collageninduced murine arthritis. Int Arch Allergy Immunol 133(1) : 19-28, 2004

40. Mor G, Sapi E, Abrahams VM, Rutherford T, Song J, Hao XY, Muzaffar S, Kohen F:Interaction of the estrogen receptors with the Fas ligand promoter in human monocytes. J Immunol 1; 170(1) : 114-22, 2003

41. Piccotti JR, Chan SY, Li K, Eichwald EJ, Bishop DK: Differential effects of IL-12 receptor blockade with IL-12 p 40 homodimer on the induction of CD 4+ and CD 8+ IFN- $\gamma$ amma-producing cells. J Immunol 15 ; 158(2) : 643-8, 1997

42. Hsieh CS, Macatonia SE, Tripp CS, Wolf SF, O'Garra A, Murphy KM : Development of Thl CD4+ T cells through IL-12 produced by Listeriainduced macrophages. Science $23 ; 260(5107)$ : 547-9, 1993

43. Correale J, Arias M, Gilmore W: Steroid hormone regulation of cytokine secretion by proteolipid protein-specific $\mathrm{CD} 4+\mathrm{T}$ cell clones isolated from multiple sclerosis patients and normal control subjects. J Immunol 1 ; 161(7) : 3365-74, 1998

44. Mowat AM, Steel M, Leishman AJ, Garside P: Normal induction of oral tolerance in the absence of a functional IL-12-dependent IFN-gamma signaling pathway J Immunol 1;163(9):4728-36, 1999

45. Goto M, Ono H, Takano-Ishikawa Y, Shinmoto H, Yoshida M : Mac 1 positive cells are required for enhancement of splenocytes proliferation caused by bisphenol a. Biosci Biotechnol Biochem 68(1) : 263-5, 2004

46. McMurray RW: Sex hormones in the pathogenesis of systemic lupus erythematosus. Front Biosci 1; $6:$ E193-206, 2001

47. Sanchez R, Nguyen D, Rocha W, White JH, Mader S: Diversity in the mechanisms of gene regulation by estrogen receptors. Bioessays 24(3) :244-54, 2002 